\title{
Arranging support for collective learning in rural areas of Germany
}

Wiebke Wellbrock ${ }^{1}$, Birte Nienaber ${ }^{2}$, Michael Kriszan $^{3}$, Robert Nadler ${ }^{4}$, Wioletta Frys ${ }^{5}$, Dirk Roep $^{1}$

More than ever, globalization puts Europe's rural areas at the centre of competing claims between agriculture, residents, nature protection (or exploitation) practices, tourism, recreation and industry parks. To create resilient rural areas which take opportunity from globalisation asks diverse development actors to work jointly towards a common development vision.

To arrive at a common development vision requires diverse actors to learn to work together (Roep et al. 2009). It requires actors to develop synergy, joint development visions and joint development activities, for which they need to source and pool knowledge and capacities (Collinge and Gibney 2010, Gibney 2011). Collective learning is thereby regarded as 'the diversity of adaptations, and the promotion of strong local social cohesion and mechanisms for collective action' (Adger et al. 2005 p. 1038).

\footnotetext{
${ }^{1}$ Rural Sociology Group, Wageningen University, The Netherlands

${ }^{2}$ Department of Geography, Working Group "European Regional Studies”, Universität des Saarlandes/Saarland University, Germany

3 Fachhochschule Südwestfalen, Institut für Green Technology \& Ländliche Entwicklung (i.green), Germany

${ }^{4}$ Leibniz-Institut für Länderkunde, Germany

${ }^{5}$ Kreisverwaltung des Saarpfalz-Kreises, Europaangelegenheiten und Partnerschaften, Homburg, Germany
} 
Current arrangements to support collective learning for resilience in rural areas (such as LEADER) have, however, received numerous criticisms with regard to their impact on facilitating participatory development and social inclusion (Cleaver 2002, Amin 2004, Shortall 2008, Shucksmith 2010). These criticisms call for alternative modes of arranging public support. Yet, how can public support for collective learning in rural areas best be arranged?

In this chapter, we explore how public support for collective learning is arranged in two rural areas of Germany: Sankt Wendeler Land in the federal state of Saarland and the Oberlausitzer Heide- und Teichlandschaft in the Free State of Saxony ${ }^{6}$. After introducing the case study areas, a framework to analyse and reflect on arrangements to support collective learning in rural areas will be presented. Then, the methods used for data collection and analysis will be described, and some background information on the organisation of support for collective learning in Germany will be provided. It will be shown how public support is operationalized and how beneficiaries evaluate the arranged support in the case study areas. Subsequently, differences in institutional arrangements to support collective learning in the respective case study areas will be discussed. It will be shown that in order to arrange public support for collective learning successfully, the operation of public support programmes needs to be delegated to

6 This chapter is based on research undertaken within WP4 Capacity building, governance and knowledge systems of the project 'Developing Europe's Rural Regions in the Era of Globalisation (DERREG), financed by the 7th Framework Programme of the European Commission. The paper only reflects the views of the authors, and the Commission cannot be held responsible for any use which may be made of the information contained therein. 
agents embedded within the area. These agents need to dispose of access to wider networks of groups and networks within and outside the area. This way, they are able to include a wide range of development actors and connect them to the appropriate supporters. In this process, the roles of shared leadership is crucial (Horlings 2012). An arrangement that works well in one area can therefore not be used as a blueprint to make arrangements in another area.

\section{Case study areas}

Explorative research was carried out in the LEADER region 'Sankt Wendeler Land' in the federal state of Saarland and the LEADER region 'Oberlausitzer Heideund Teichlandschaft' (English: Upper Lusatian Heath and Pond Landscape, hereafter OHTL) of the Free State Saxony. As shown in figure 1, Sankt Wendeler Land is located at the western border of Germany while OHTL is located at the eastern border of Germany.

\section{[Insert figure 1 here- Portrait]}

Figure 1 Location of case study areas indicated by stars

The LEADER region 'Sankt Wendeler Land' is equivalent to the administrative unit 'County Sankt Wendel' which, according to the European urban-rural typology, is classified as predominantly rural (Eurostat 2012). The county covers $476.2 \mathrm{~km}^{2}$ and inhabits 93.290 people (196 inhabitants $/ \mathrm{km}^{2}$ ) (KuLanI 2007). It consists of eight municipalities and its centre is the city of St. Wendel (KuLanI 2007). Most inhabitants work in the service sector outside of the county and the income is relatively high in comparison to other rural areas of Saarland (KuLanI 2007). Within the county, agriculture, forest and timber work are dominating the landscape. Tourism is another important source of income. Interesting to note is that Saarland has a long history of 
being shifted between France and Germany during the last 200 years. This is often named as the reason for the closed social networks and social cohesion in Saarland and the saying that each person in Saarland knows somebody and at the end is connected to any other person living in Saarland.

The LEADER region OHTL covers parts of the County Bautzen, which is classified as intermediary in the European urban-rural typology (Eurostat 2012). The northern, more sparsely populated parts of the LEADER region are protected as a UNESCO biosphere reserve. OHTL consists of 17 municipalities and towns and comprises an area of $657 \mathrm{~km}^{2}$. It provides home to 86,403 people (132 inhabitants $\left./ \mathrm{km}^{2}\right)$, of which 42,480 live in the region's economic centre of Bautzen city (Panse 2007). The ponds of the region are an important economic source, as they are used for fish production. Also agriculture and nature conservation play an important role in shaping the landscape of the area. Unlike Sankt Wendeler Land, the development of OHTL, as for the whole Free State of Saxony, is marked by an on-going process of economic catch-up to the German national level and characterised by high unemployment, a shrinking and ageing population and a loss of young, well-educated people due to outmigration. Most parts of the OHTL belong to the settlement area of the Sorbs, a minority living in Saxony and the South of Brandenburg. They still practise their own culture and language and through this they significantly coin the area.

The two case study areas are exemplary for two major divergences in political as well as socio-economic backgrounds of rural areas in Europe: a case study area representative of former West-Germany and a case study area representative of former East-Germany. Comparing the two German cases has thus implications for supporting collective learning within the wider European context. At the same time, both case 
study areas are governed under the same national policy scheme, increasing the comparability and omitting confounding factors that often influence comparisons of rural areas between two or more countries. In addition, both case study areas are part of wider border regions, sharing similar experiences with cross-border activities.

\section{Theoretical framework}

Joint learning and innovation for building collective capacity and resilience has mainly been studied with regard to the production and transfer of new, scientific knowledge and human capital within high-tech, science, media, and communication and information industries in urban, economic centres (Woods 2009). The aim of these 'learning region' studies has been to analyse how public support can facilitate spatial proximity and the formation of 'clusters' which then facilitate a rapid knowledge spillover and the provision of related human capital from academia to businesses (Asheim 1996, Morgan 1997, Storper 1993, Rutten and Boekema 2007, Florida 1995, Wolfe 2002, Etzkowitz and Leydesdorff 2000). The success of support for collective learning is argued to depend on arranging effective, co-operative and operational partnerships between actors of the state, academia and industry (Asheim, 2007, Florida, 1995).

Yet, learning regions are argued to fail to represent most present day regions (Oughton et al. 2002). In particular, the business-academia-government linkages have been argued to fail to serve the study of support for place-based learning in rural areas (Terluin 2003, Dargan and Shucksmith 2008, Shucksmith 2009, Wellbrock et al. 2012), grounded in the particularities of place: that is assets, challenges and political dynamics (Woods 2007).

Wellbrock et al. (2012) put forward an amended framework, offering an integrated perspective in studying the public support for collective learning in rural 
areas. In contrary to the usual (or conventional) 'learning region' framework, studying arrangements between partners of the triple helix (Etzkowitz 2003) in support of regional learning and innovation in economic core regions, the integral framework considers all joint development activities undertaken in a rural area and the wide range of actors engaged (Roep et al. 2009).

\section{[insert figure 2 here- Portrait]}

Figure 2: Analytical framework, adjusted from Wellbrock et al. 2012

As figure 2 shows, instead of focussing on 'businesses', the amended framework focuses on 'rural areas' and the diverse actors and activities contributing to the development of the area. These areas can coincide with administrative areas but not necessarily. Instead the areas distinguish themselves by a common political history, culture and identity as well as socio-economic development. The domain 'academia' is replaced by the 'knowledge support structure', including all potential public as well as private agents and agencies that can facilitate collective learning processes in grassroots development initiatives. These can include, for example, public and private knowledge institutes, private consultancy services, public institutes, NGOs, private development experts as well as grassroots development initiators acting as knowledge facilitators (Wellbrock et al. 2012). Finally, the revised framework refers to the domain 'public administration', referring to those involved in the making and implementation of supporting policies for collective learning in rural areas.

Operational interfaces between the different domains and connecting the various actors and activities are critical focal points of the theoretical framework, because they enable the different actors to learn together and from one another, thereby acting as channels for dialogue and cooperation (Nyhan 2007). The revised framework proposed 
by Wellbrock et al. (2012) thus focuses on highlighting existing interfaces that aim to support and facilitate knowledge processes, exploring dimensions of knowledge building, collaborative social learning and the re-embedding of local knowledge in grassroots development initiatives, as indicated by the arrows a, b and c.

The revised framework is able to guide research along three lines (Wellbrock et al. 2012). First, it helps to map supporting policies and programmes as well as actors operating these. Secondly, it helps to map existing interfaces and to analyse how these are arranged; describing their constitutive agreement and the operational interfaces with respect to: the operational agents, the delegated tasks and roles and associated rules and regulations and the shape of the operational interface. Finally, the framework can be used to evaluate and compare existing supportive arrangements, and particularly whether their operational features are working well or not. The second and third step can also be done in an interactive way, jointly with involved members of public administration, knowledge facilitators and beneficiaries.

Based on the mapping, analysis and (interactive) evaluation, an understanding of why some arrangements work better than others can be generated. On the basis of these findings, lessons can be drawn on how public support can best be arranged in order to facilitate collective learning in rural areas.

\section{Methodology}

The study extends on empirical research conducted within a larger European research project (Roep et al. 2011). Within this research project, explorative research was carried out in both case study areas simultaneously between February 2009 and June 2011. Three research lines were followed: 
First, an overview of public policies to support collective learning and the facilitating knowledge support structure was generated. This was done through extensive literature reviews and semi-structured expert interviews with relevant informants (ranging from 10 to 15 in each case study area).

Secondly, in each case study area, 10-15 grassroots development initiatives, covering diverse fields of development (agriculture, nature \& landscape development, civic \& community development and economic activities), and receiving public support for collective learning were inventoried, regarding: their aim, initiators, actors engaged, the type of support received and the relevant supporting policy arrangement. The inventory was done using semi-structured interviews. Operational interfaces were identified through internet research and snowball-sampling.

Finally, in each case study area, four to five promising operational interfaces were selected for an in-depth study involving face-to-face interviews and group discussions with selected key informants, from public administration, the knowledge support structure and grassroots development initiatives focussing on factors that supported and/or constrained their achievements.

In addition, a substantial part of the results gathered in Sankt Wendeler Land are based on qualitative interviews that were carried out during the LEADER evaluation process and the mid-term evaluation of the LEADER regions in 2008-2010.

The research and analysis gave specific attention to describing the operational interfaces with respect to: the operational agents; the delegated tasks and roles and associated set of rules and regulations (regimes); and the shape of the operational interface.

\section{General organisation of public support for collective learning in rural Germany}


In order to understand how support for collective learning can be best arranged in Germany's rural areas, it is first necessary to get an overview of how public support is actually arranged.

In Germany, public support for collective learning is arranged hierarchically at different public administrative scales. The majority of public subsidies are derived from European funds. Consequently, the way in which public support is arranged within a rural area is highly dependent on the thematic orientation of the EU Commission.

At national level, the Federal Ministry of Food, Agriculture and Consumer Protection incorporates the European goals into the National Strategic Plan for the Development of Rural Areas. This plan forms an interface between the European Rural Area Development Fund and the development concepts of the different federal states in Germany. The Ministry and the different federal state governments collaborate in a task force which aims to finance public or private institutes which are involved in rural development initiatives in different rural areas.

At federal state level, the main political task is to facilitate an integrated rural development approach (Integrierte Ländliche Entwicklung). In doing so, the federal state allocates and redirects financial resources and policies towards different development fields.

At county and municipality level, specific integrated rural development concepts (Integriertes Ländliches Entwicklungskonzept: ILEK) are formulated. The integrated rural development concept can then be used by the counties and municipalities to apply for funds from the integrated rural development approach or from the LEADER programme, which has higher subsidy rates than the national programme. The 
application for funds is highly competitive and only the best integrated rural development concepts are considered for the LEADER programme.

Both of our case study areas have been LEADER regions since 2002. The LEADER programme is regionally managed by a Local Action Group (LAG), consisting of representatives from public administration, business and civic organisations. In each case study area, the LAG is a formal association. It is supported by 'coordination circles', a group consisting of public and private members, who control and evaluate the development progress in the LEADER region. The coordination circle is assisted by a regional management team that elaborates development projects for the coordination circle. In addition, several themed working groups are run that are open for members of the general public to come and elaborate development project ideas.

The way in which public support for collective learning is arranged in different rural areas is thus arguably restricted, because although the local circumstances vary strongly, all development projects have to fit standardised EU criteria on the local level.

\section{Results}

Despite the common public administrative structure and institutional arrangements that both case study areas are subordinated to, the features of operational interfaces and the actual support differed considerably: the agents and agencies differed, as well as their delegated tasks and roles and the shape of operational interfaces providing direct public support for collective learning in grassroots development initiatives.

LEADER Region Sankt Wendeler Land 
In Sankt Wendeler Land, operational interfaces were common in form of publicprivate partnerships. Public and private agents engaged, for example, jointly in associations or public-private development projects. Public administration also selected existing grassroots development initiatives to mediate public support. One such example is the association 'Cultural Landscape Initiative St. Wendeler Land' (referred to as KuLanI in fig. 3) which focusses on preserving and developing the cultural landscape of St. Wendeler Land.

\section{[insert figure 3 here- PORTRAIT]}

Figure 3 Arrangements to support collective learning in Sankt Wendeler Land

In 2002, the 'Cultural Landscape Initiative St. Wendeler Land' successfully applied for funds from the LEADER + programme, and in 2007 again from the LEADER programme, in order to realize their regional development concept 'Local commodity market Sankt Wendeler Land'. Since 2002, the concept of the 'Cultural Landscape Initiative St. Wendeler Land' had thus formed the basis for an integrated development approach along three lines: awareness raising, marketing of local products and supporting cultural tourism. During the LEADER phase 2007-2013, a fourth line was added, alternative energy production.

The implementation of the development concept of the 'Cultural Landscape Initiative St. Wendeler Land' had various implications. First, the grassroots development initiative 'Cultural Landscape Initiative St. Wendeler Land' was transformed into a legal association, taking members of public administration on board. As figure 3 shows, in this constellation, it became the LAG for the LEADER region Sankt Wendeler Land. Within the different development lines of the concept, the 
'Cultural Landscape Initiative St. Wendeler Land' delegated different roles and tasks to other operational agents and agencies in the area.

As figure 3 shows, in order to realize the cultural tourism line, 'Bosener Mühle' a centre for arts within Sankt Wendeler Land, was chosen as operator. Its task was to coordinate and elaborate on cultural and tourism projects within the area that were able to fulfil the development goals of the concept. In doing so, it facilitated other development projects, such as the cultural history awareness raising campaign 'Stories from Europe' in collaboration with the 'European Academy Otzenhausen' (see fig. 3). Other activities in the development line 'awareness raising' initiated by 'Cultural Landscape Initiative St. Wendeler Land' included an educational network with local schools and the school camp 'BiberBurg Berschweiler'. Finally, as figure 4 shows, for the development line 'local marketing', the 'Cultural Landscape Initiative St. Wendeler Land' organized a local commodity market 'Lokalwarenmarkt St. Wendeler Land'. To support the marketing of local products, the 'Cultural Landscape Initiative St. Wendeler Land' further initiated projects such as the 'Distribution logistics for local products' and the 'Four-in-hand of marketing' as shown in figure 3. For these latter projects, the 'Cultural Landscape Initiative St. Wendeler Land' also engaged with the knowledge support structure in order to facilitate collective learning in the area.

\section{LEADER Region OHTL}

Turning towards the LEADER region OHTL, the LAG 'Association Oberlausitzer Heide- und Teichlandschaft' was formed in response to the establishment of the LEADER + region in 2002. In contrast to the LAG in Sankt Wendeler Land, it did not connect to an already existing grassroots development initiative. Instead, a marketing firm with a strong network of contacts inside and outside the area was 
assigned with the task of formulating an integrated development plan for OHTL. A LAG was formed with public administration, local businesses and civic organisations out of the LEADER programme requirements for a public-private partnership.

\section{[insert figure 4 here- PORTRAIT]}

Figure 4 Arrangements to support collective learning in OHTL

Central to the integrated development concept was the conservation and development of nature and the Sorbian culture, because they were seen as unique economic assets in the area. As a result, figure 4 shows that next to the LAG, other operational interfaces identified in OHTL were either focussing on nature and landscape management or on Sorbian culture and cultural tourism.

The operational interface 'Krabat e.V.' shown on the left side of figure 4 was, for example, concerned with the marketing of regional products and the development of tourism in OHTL. Starting out as a grassroots development initiative, Krabat e.V. eventually initiated other networks and grassroots development initiatives aiming at producing and marketing regional products and tourism. In this course, it transformed from a grassroots development initiative into an umbrella organisation for the marketing of regional products in the area. As an umbrella, it owned the licence for the brand 'Krabat', which could be used by producers in the area against payment of a fee (for example Krabat milk world (German: Krabat Milchwelt, see figure 4). 'Domowina' also supported activities of Sorbian associations in the area. The operational interface 'Sorbischer Kulturtourismus' started as a grassroots initiative, consisting of regional organizations, associations and enterprises from the (cultural) tourism sector. Meanwhile, it initiated several activities, projects and initiatives related to gastronomy and Sorbian handicraft. Similar to Krabat e.V., the 'UNESCO Biosphere Reserve 
OHTL' operated as an interface and initiated development projects such as the production of bio carp (Oberlausitzer BioKarpfen) shown in the right-hand corner of figure 4. Today, the production and marketing of bio carp are operating almost independent of the operational interface through regional fish farming firms and external fish processing companies. One can therefore argue that some of the operational interfaces supporting Sorbian associations started out as (grassroots) development initiatives themselves and shifted towards being incubators of new, independent grassroots development initiatives.

Figure 4 further shows that in OHTL the knowledge support structure consisted, next to public schools and vocational training institutions, mainly of the University of Applied Sciences Zittau/Görlitz, and the Dresden Technical University. These were located outside the OHTL area. Within the area, the Sorbian Institute in Bautzen might be mentioned as a partner for all initiatives dealing with Sorbian issues. Unlike in Sankt Wendeler Land, the engagement of the knowledge support structure was not linked to the activities of the LAG and the development concept, but organised through different operational interfaces. As figure 4 shows, there were two main ways in which the knowledge support structure facilitated collective learning in grassroots development initiatives. First, they sent students to the grassroots development initiatives as interns or when writing degree theses. Secondly, they provided the latest scientific knowledge to grassroots development initiatives. Here, the role of professors/scientists was considered more important than the role of students.

Evaluation of public support for collective learning in the case study areas

Comparing figures 3 and 4 shows that the shape of the operational interfaces, the operational agents and agencies as well as the delegated tasks and roles differed 
considerably between the two case study areas. These differences were also reflected in the evaluation of the available support by the beneficiaries.

In both case study areas, beneficiaries argued to be strongly dependent on public funds for their activities. In OHTL this meant that self-sustaining initiatives were the exception. A great deal of initiative work could only be initiated because a public funding scheme was available. However, this form of support included difficult bureaucratic procedures and long application phases for short funding periods. Complex administration and public expenditure guidelines thus served as a disincentive for applying for public funds, and hence to put development ideas into practise. In addition, short funding periods and unclear future perspectives were argued to be counterproductive for long-term development processes.

The strong involvement of public administration in the operation of public support was perceived differently in the case study areas. In OHTL, public administration was argued to strongly determine the activities of development initiatives, making them dependent on political agenda setting. Electoral changes in public policies resulted in frequent changes of arrangements, prevented the establishment or institutionalisation of long-term partnerships as well as long-term, joint development visions in the area. Beneficiaries also felt a spatial and cognitive distance between public administration and their own needs, resulting in a perceived lack of interest and attention towards their development ideas. Moreover, application for the limited, public funds resulted in a strong competition, long, complex bureaucratic procedures and small revenues for short funding periods. At the same time, public funds were often invested in hard, visible infrastructure that could serve to gain votes in the next election campaign. 
In Sankt Wendeler Land, the resulting nearness to public administration was appreciated, because initiatives benefited from a high social reputation and support of politically independent circles. Nevertheless, the high involvement of public administration was also perceived as a constant form of control.

Another example of different perceptions of public support is the attempt of public administration to establish networks. In OHTL, the initiation of networks by public administration was argued to be too artificial to have a significant impact. People across long geographical distances where brought together, which facilitated knowledge exchange but did not support everyday contacts in the region. In addition, it was argued that even if today efficient networks existed, they would be endangered by a social perforation, as more and more potential stakeholders leave the region. The social perforation was regarded as a challenge in OHTL. On the one hand, it helped to form good work relations between certain actors, because the relations were based on mutual trust and informal work routines. However, these positive effects only provided advantages for the ones involved. On the other hand, interviewed actors mentioned that there were always the same people involved in activities as no others were present in the area or did not immigrate as new actors.

In Sankt Wendeler Land, in contrast, the establishment of networks, by public administration as well as knowledge bodies, was highly welcomed among grassroots development initiatives, and the networks tended to persist after initiation. Particularly women appreciated the opportunity to network. During network meetings, informal talks with scientists, who were mostly known personally, were valued in order to access the latest knowledge and information. Networking amongst grassroots development initiatives in the region was another important source of support. Support for collective 
learning was also provided to the initiatives by networks among their own ranks, as these were often linked to federal umbrella organisations.

With regard to the involvement of the knowledge support structure, these appeared to play a minor role for grassroots development initiatives in Sankt Wendeler Land and OHTL. Still, in OHTL, knowledge bodies were well networked within the region and the cooperation between regional development initiatives and knowledge facilities was perceived as working well. Students were hereby important actors in building bridges between grassroots development initiatives and knowledge institutes. Expert knowledge from companies and individuals was also highly valued by initiatives. In Sankt Wendeler Land, regional universities and academies involved less frequently with grassroots development initiatives, because of too high costs associated with scientific research and resources. Nevertheless, also here students joined occasionally initiatives for thesis and internship work.

\section{Discussion}

To conclude the chapter, let us return to the opening question of how public support for collective learning can best be arranged to enhance resilient rural areas.

Comparing the two cases, one can argue that in order to arrange public support for collective learning successfully, it is necessary to delegate operational tasks and roles to agents with extensive networks in and outside the area. These operational agents can arguably be regarded as 'spiders' in a web of networks (Nyhan 2007). As the results indicate, operational agents are able to mediate between the different worlds of policy, knowledge and development practitioners. As such the 'Cultural Landscape Initiative Sankt Wendeler Land' was able to facilitate projects connecting all three domains of the analytical framework. In addition, operational agents can take a lead in 
coming to joint development vision. This was for instance the case of the regional management of the LAG who was able to involve the Sorbian minority in the joint development process. One implication is therefore that in order to create resilient areas, public administration needs to seek out operational agents that are well rooted in the area and thus have networking abilities. These agents have the ability to connect their networks to the institutional environment, influencing agenda setting and changing of rules (Horlings 2012). This way, public support for collective learning can be better attuned to the needs of grassroots development initiatives.

In order to create resilient rural areas, it is necessary that diverse development actors learn to work together (Roep et al. 2009). A further role of operational agents is therefore to connect, include and coordinate as many diverse actors as possible in the development process. The cases demonstrate that the best way to include diverse development actors is to connect to already existing networks and cohesive groups in the area. In OHTL, for example, the Sorbian minority was strongly involved in the development process. They received operational tasks from public administration or the LAG, incubated further development initiatives and carried out development activities in the area. In Sankt Wendeler Land, the 'Cultural Landscape Initiative Sankt Wendel' was able to use the strong social ties and networks which evolved historically through the shifting of Saarland between Germany and France. Through empowering the 'Cultural Landscape Initiative Sankt Wendel' with operative and decision power, public administration was arguably able to unravel a whole network of operational agents, networks and development projects, engaging other grassroots development initiators as well as the knowledge support structure. One further implication that can be drawn from this example is that in order to create resilient rural areas, it is necessary to find the right 
scale of operation. The results suggest that the scale of operation should be related to areas sharing a common regional identity. This can arguably trigger residents to engage in development activities.

Taking the need for a 'spider' and the need to mobilize and connect existing social groups and networks, the results once again point to the importance of shared leadership which builds on trust, commitment, energy and joint development agendas (Horlings 2012). By doing so, operational agents contribute to the building of shared knowledge and understanding, capacity and synergy between stakeholders (Collinge and Gibney 2010).

Social perforation, out-migration and economic hardship make it, however, difficult for operational agents to engage diverse actors in the development process. In OHTL, it was thus argued that the attempt of public administration to initiate networks in the area remained unsuccessful. In addition, in cases where public administration is taking the leadership, this was perceived negatively by grassroots development initiatives. A clash of interests, dependencies on political agenda settings as well as a high dependence on short funding periods was reported. Also Padt (2012) argues, that the managerial style of leadership often shown by public administration with a clear focus on short-term solutions does not help sustainable development. Indeed, Friedrich (2003 p. 22) remarked that most grassroots development initiatives in Upper Lusatia although capitalized with different public funding resources - were working without visible success or had already disappeared.

Leadership thus needs to be embedded in and needs to draw on networks, trust, cooperation and commitment of people (Horlings and Padt 2011). Leaders can therefore be regarded as 'boundary spanners', bridging between their own networks, public 
administration and the knowledge support structure (Horlings, 2010, p. 11). In addition, they are arguably able to motivate residents, to bridge different interests and connect actors across conventional development domains. Leaders are therefore required to frame new regional concepts and agendas, facilitate coalitions and have the capacity to act within the institutional context (Horlings 2012). This way, a joint, place-based development vision for the creation of resilient rural areas can be facilitated.

\section{Conclusion}

Comparing operational features of arrangements to support collective learning in Sankt Wendeler Land and OHTL raised several issues concerning the arrangement of effective (public) support for developing resilient rural areas that go beyond the particularities of the German context. Crucial for creating resilient rural areas are leaders able to build collective agency and thus support the working together of diverse actors and activities towards a common development vision. Connecting different development actors is best done by tapping into culturally and historically grown networks and groups (as being place-based) and connecting these via operational agents stemming from and being familiar with the area. At the same time, it requires an alignment between grassroots development initiative and supportive public policies with their and aims, procedures and programmes. Successful arrangements to support collective learning appeared to delegate executive and decision powers from the start to operational agents and agencies rooted in the area. Ideally, these dispose of a wide network of different contacts outside and inside the area: they know the particular assets and available capacities, the initiators or visionary, collaborative leaders and bonding and bridging capacities. This way, the inclusion of a wide range of actors in developing a resilient area can be facilitated. 


\section{Acknowledgements}

We would like to thank our fellow DERREG research partner Joachim Burdach for his engagement. We are also grateful to the European Commission for funding the research within the 7th Framework Programme.

\section{References}

Adger, W. N., Hughes, T. P., Folke, C., Carpenter, S. R. and Rockström, J. (2005) 'Social-Ecological Resilience to Coastal Disasters', Science, 309(5737), 10361039.

Amin, A. (2004) 'Regions Unbound: Towards a New Politics of Place', Geografiska Annaler. Series B, Human Geography, 86(1), 33-44.

Asheim, B. (1996) 'Industrial districts as 'learning regions': A condition for prosperity', European Planning Studies, 4(4), 379-400.

Cleaver, F. (2002) 'Reinventing Institutions: Bricolage and the Social Embeddedness of Natural Resource Management', The European Journal of Development Research, 14(2), 11-30.

Collinge, C. and Gibney, J. (2010) 'Connecting place, policy and leadership', Policy Studies, 31(4), 379-391.

Dargan, L. and Shucksmith, M. (2008) 'LEADER and Innovation', Sociologia Ruralis, 48(3), 274-291.

Etzkowitz, H. (2003) 'Innovation in Innovation: The Triple Helix of University-IndustryGovernment Relations', Social Science Information, 42(3), 293-337.

Etzkowitz, H. and Leydesdorff, L. (2000) 'The Dynamics of Innovation: From National Systems and 'Mode-2' to a triple helix of University-Industry-Government Relations', Research Policy, 29(2), 109-123.

Eurostat (2012) 'Urban-rural typology', [online], available: http://epp.eurostat.ec.europa.eu/statistics_explained/index.php/Urbanrural typology\#Database [accessed

Florida, R. (1995) 'Towards the learning region', Futures, 27(5), 527-536.

Friedrich, W. (2003) 'Wirtschaftsgeschichte und Wirtschaftspolitik in der Lausitz' in W., S. and Zundel, S., eds., Regionale Entwicklung in der Lausitz: Auf der Suche nach einem wirtschaftlichen Profil, Berlin, Germany: be.bra wissenschaften, 1455. 
Gibney, J. (2011) 'Knowledge in a "'Shared and Interdependent World"': Implications for a Progressive Leadership of Cities and Regions', European Planning Studies, 19(4), 613-627.

Horlings, I. (2012) 'Value-oriented leadership in the Netherlands' in Satorauta, M., Horlings, I. and Liddle, J., eds., Leadership and Change in Sustainable Regional Development, Oxon, UK: Routledge, 252-271.

Horlings, I. and Padt, F. (2011) 'Leadership for Sustainable Regional Development in Rural Areas: Bridging Personal and Institutional Aspects', Sustainable Development, n/a-n/a.

KuLanl, K. S. W. L. e. V. (2007) Lokalwarenmarkt St. Wendeler Land 2015+. Regionales Entwicklungskonzept der LAG St. Wendeler Land, St. Wendel.

Morgan, K. (1997) 'The learning region: institutions, innovations and regional renewal', Regional Studies, 31(5), 491-503.

Nyhan, B. (2007) 'Building learning regions for innovation in Europe: a challenge for education and training' in Gustavsen, B., Nyhan, B. and Ennals, R., eds., Learning together for innovation: promoting learning regions, Luxembourg: Office for Official Publications of the European Communities, 16-34.

Oughton, C., Landabaso, M. and Morgan, K. (2002) 'The Regional Innovation Paradox: Innovation Policy and Industrial Policy', The Journal of Technology Transfer, 27(1), 97-110.

Padt, F. (2012) 'Leadership and scale' in Satorauta, M., Horlings, I. and Liddle, J., eds., Leadership and Change in Sustainable Regional Development, Oxon: Routledge, 60-79.

Panse, L. (2007) Integriertes Ländliches Entwicklungskonzept "Oberlausitzer Heideund Teichenlandschaft", Bautzen.

Roep, D., Horlings, I. and Wielinga, E. (2009) De werkvloer van een Kennisnetwerk Vitaal Platteland. Kennis maken met regionale kennisarrangementen, Den Haag, the Netherlands: LEI Wageningen UR.

Roep, D., Wellbrock, W., Kairyte, E., Farrell, M., Mahon, M., Frys, W., Nienaber, B., Kriszan, M., Nadler, R., Burdack, J. and Dominguez Garcia, L. (2011) DERREG D4.4 Summary Report, Wageningen, The Netherlands.

Rutten, R. and Boekema, F. (2007) The Learning Region: Foundations, State of the Art, Future, Cheltenham, UK: Edward Elgar Publishing Ltd.

Shortall, S. (2008) 'Are rural development programmes socially inclusive? Social inclusion, civic engagement, participation, and social capital: Exploring the differences', Journal of Rural Studies, 24(4), 450-457.

Shucksmith, M. (2009) 'Disintegrated Rural Development? Neo-endogenous Rural Development, Planning and Place-Shaping in Diffused Power Contexts', Sociologia Ruralis, 50(1), 1-14. 
Shucksmith, M. (2010) 'Disintegrated Rural Development? Neo-endogenous Rural Development, Planning and Place-Shaping in Diffused Power Contexts', Sociologia Ruralis, 50(1), 1-14.

Storper, M. (1993) 'Regional "worlds" of production: learning and innovation in the technology distrcts of France, Italy and the USA', Regional Studies, 27(5), 433455.

Terluin, I. J. (2003) 'Differences in economic development in rural regions of advanced countries: an overview and critical analysis of theories', Journal of Rural Studies, 19(3), 327-344.

Wellbrock, W., Roep, D. and Wiskerke, J. S. C. (2012) 'An integrated perspective on rural regional learning', European Countryside, 4(1), 1-16.

Wolfe, D. A. (2002) 'Social capital and cluster development in learning regions' in Holbrook, J. A. and Wolfe, D. A., eds., Knowledge, Clusters and Learning Regions, Kingston: Queens University.

Woods, M. (2007) 'Engaging the global countryside: globalization, hybridity and the reconstitution of rural place', Progress in Human Geography, 31(4), 485-507.

Woods, M. (2009) Literature Review and Conceptual Framework. Synthesis and Contextualisation of Research and Development of an Interpretative Model, Aberystwyth, UK: Aberystwyth University. 